\title{
La representación del espacio urbano en las canciones de Zebda. Análisis sistémico funcional ${ }^{1}$
}

\author{
Ana María IGLESIAS BOTRÁN \\ Universidad de Valladolid \\ Departamento de Filología Francesa y Alemana \\ anabotran@fyl.uva.es
}

Recibido: $28 / 10 / 2011$

Aceptado: 06/02/2012

\begin{abstract}
Resumen
Los lugares en los que viven las personas dentro del ámbito urbano son una muestra de las diferencias económicas y sociales que se reproducen en la sociedad. A través de la distribución del espacio se establecen límites en los que entran o quedan excluidos las minorías y demás grupos. Por su parte, la canción ha sido siempre un reflejo de la historia de las sociedades y en este caso no parece ser una excepción. Para comprobar esta afirmación, hemos seleccionado y analizado desde el Análisis Crítico del Discurso aplicando la gramática sistémico-funcional de Halliday (2004) la representación discursiva del espacio urbano en los textos de las canciones que se refieren a esta cuestión en la discografía del grupo musical Zebda.
\end{abstract}

Palabras clave: canción, análisis crítico del discurso, espacio urbano, gramática sistémico-funcional

\section{La représentation de l'espace urbain dans les chansons de Zebda. Analyse systémique fonctionnelle}

\section{Résumé}

Les endroits où les personnes habitent dans le contexte urbain manifestent souvent les différences économiques et sociales qui se reproduisent dans la société. A partir de la distribution de l'espace, on établit des limites dans lesquelles entrent ou sont exclus les minorités ainsi que d'autres groupes. De son côté, la chanson a toujours été un reflet de l'histoire des sociétés et, dans ce cas particulier, elle ne semble pas être une exception. Pour pouvoir vérifier cette affirmation, nous avons sélectionné et analysé en nous basant sur l'Analyse Critique du Discours et en appliquant la grammaire systémiquefonctionnelle de Halliday (2004) la représentation discursive de l'espace urbain dans les textes des chansons qui font partie de la discographie du groupe musical Zebda.

Mots clés: chanson, analyse critique du discours, espace urbain, grammaire systémique-fonctionnelle.

\footnotetext{
${ }^{1}$ Este artículo se enmarca en la investigación financiada por la Consejería de Educación de la Junta de Castilla y León, en el marco del proyecto titulado "40 años de comunicación musical. La función social de la canción popular en España, Francia, Reino Unido e Irlanda. Un análisis lingüístico" (VA084B11-1) concedido por orden EDU 1174/2010; publicada en el B.O.C.Y.L. con fecha 29/03/2011.
} 


\title{
The Discursive Representation of Urban Space in Songs by Zebda. A Systemic-Functional Analysis
}

\begin{abstract}
The places where people live within urban environments reveal economic and social differences within society.In that sense, minorities are included or excluded from spatial limits. . For their part, songs have always been reflections of social history, and in this case, they are not an exception. Using Critical Discourse Analysis and applying Halliday's (2004) systemic functional grammar,, this article analyzes the discursive representation of urban space in songs in the discography of the French band Zebda.
\end{abstract}

Key words: song, critical discourse, urban space, systemic functional grammar.

\section{Referencia normalizada}

Iglesias Botrán, A. M., (2012) "La representación del espacio urbano en las canciones de Zebda. Análisis sistémico funcional”. Thélème, Vol. 27, 191-210.

Sumario: Método de análisis. Análisis del título de las canciones. Análisis de las personas representadas: primera y tercera persona, audiencia. Análisis de la Transitividad: procesos materiales, procesos mentales, procesos verbales, procesos de comportamiento y procesos relacionales. Conclusión

Desde la sociología se considera que la segregación es una forma más o menos institucionalizada de distancia social que se produce en función de una separación en el espacio (Fijalkow, 2002: 53). A lo largo de la historia, la posición espacial de los colectivos sociales o clases más desfavorecidas ha ido variando, sin embargo en toda ciudad ha habido y hay algún tipo de distinción social visible en la distribución y ocupación del espacio. Asimismo, se observa que la separación de la población en relación con la riqueza o clase social que se da en Europa suele ser de tipo socioespacial, y Francia parece no ser una excepción. Dentro del contexto urbano, el espacio es, por un lado, un elemento socializador $\mathrm{y}$, por otro, funciona como un factor de exclusión social (Bourdieu, 1988: 100), ya que las diferentes zonas de una ciudad se organizan dependiendo de la riqueza y del poder de sus habitantes. Durante el siglo XX los procesos de inmigración en Francia condicionan la distribución y organización de las ciudades y el surgimiento de espacios de segregación (Winock, 2003; Ambrosi, 2004; Noiriel, 2006). Los ciudadanos ocupan el espacio en relación a su posición en el ámbito social que viene determinada por su capital económico, cultural y social. De igual forma, existe una correspondencia entre la situación que los ciudadanos ocupan en el espacio geográfico y la distribución de los bienes en ese espacio (Bourdieu, 1988: 120-121).

Cuestiones sociales como las que se acaban de detallar se plasman en la canción popular ya que sus textos están empapados de las prácticas cotidianas, insertados en la vida social y en el imaginario común. Se trata por lo tanto de un lugar privilegiado para leer la profundidad de una cultura y de la historia (Dutheil, 2004: 17-18). 
La chanson est bien plus que la chanson; elle est une forme, un avant-propos que l'époque élabore pour dire ce qu'elle a à dire, pour signifier et faire sentir ce qui pour elle est important, ce qu'on pourrait appeler sa sensibilité (Dutheil, 2004 : 18).

La canción dedicada a los temas sociales o engagée se entiende como aquella canción o actitud intelectual del artista que, tomando consciencia de su pertenencia a la sociedad y al mundo de su tiempo, renuncia a una posición de espectador y pone su pensamiento o su arte al servicio de una causa (Bizzoni \& Prévost-Thomas, 2008: 11-12). Esto implica que la canción plasma realidad social en la que se desarrolla y constituye un discurso ideológico desde el que se pretende luchar contra determinadas situaciones que el emisor considera inadecuadas o injustas. De manera que la canción, además de cumplir las funciones propias de cualquier producto artístico (Eco, 2007: 325), es también una forma de construir y reconstruir la sociedad (Calvet, 1981: 118-119), así como un arma ideológica de lucha.

De este fenómeno surge el interés por esta cuestión, materializado en los textos de las canciones del grupo Zebda que exponen las preocupaciones de los ciudadanos franceses de segunda o tercera generación procedentes de la inmigración. Este grupo musical es muy conocido en Francia y goza del reconocimiento de la ciudadanía francesa gracias a su carrera musical en la que no faltan grandes éxitos. Zebda es considerado en la actualidad un grupo musical perteneciente a la llamada "musique française", y un grupo enmarcado en la canción comprometida, al mismo nivel de Bruant, Léo Ferré o Brassens (Marx Scouras, 2005: 88-90). De igual forma, aparecen en el trabajo de Louis-Jean Calvet "Cent ans de chanson française" (2008: $107,180,220,229,533)$ que puede considerarse un diccionario de la canción francesa del último siglo. De igual forma, existen monografías dedicadas al grupo (Marx Scouras, 2005; Reijasse, 2002) y ha sido objeto de estudios académicos recientes (Bizzoni \& Prévost-Thomas, 2008: 165-172; Iglesias Botrán, 2011).

La razón por la que hemos seleccionado los textos de las canciones de este grupo para el análisis es su interés por la representación discursiva del espacio francés vinculado a las cuestiones relativas a las minorías (Ferréol \& Jucquois, 2004: 209210; Semprini, 1997: 30). En estas canciones se realiza una representación y reivindicación de un espacio urbano en el que conviven diferentes grupos sociales, con orígenes y culturas diferentes. A parte de reclamar derechos propios de la nacionalidad francesa, muestran cómo los habitantes de estos lugares, a pesar de la precariedad, el paro y la discriminación, de forma contraria a lo que pudiera parecer, tienen buenos recuerdos y sentimientos hacia las calles y los barrios donde pasaron su infancia y primera juventud. En este macrotema se agrupan por lo tanto siete canciones del grupo musical Zebda: "Matabiau" (1995), "Ma rue" (1995), "Toulouse" (1995), "Né dans la rue" (1998), "On est chez nous" (1998) y "Du soleil à la toque" (2002). Hay que señalar que la cuestión del espacio es un tema recurrente en los textos de estas canciones, ya que incluso en un mismo disco aparecen dos canciones sobre el tema, como en el caso de "Essence Ordinaire" y "Le bruit et l'odeur", y que seis canciones a lo largo de toda la discografía muestran la importancia que el mismo tiene para el grupo Zebda. 
El objetivo de este artículo es por lo tanto analizar los textos de las canciones referidos al espacio urbano desde un punto de vista estrictamente lingüístico. El enfoque adoptado es el Análisis Crítico del Discurso y el método que hemos diseñado se centra en la gramática sistémico funcional de MAK Halliday (2004) y en la teoría de la representación de los actores sociales de Theo van Leeuwen (1996: 3270). Sin embargo, no queremos dejar de mencionar la importancia de los rasgos estéticos y poéticos de este tipo de canciones, y que, aunque nuestro estudio se centra en temas lingüísticos, es necesario tener en cuenta a la hora de la interpretación (Marc Martínez, 2008).

\section{Método de análisis}

Halliday (2004) entiende el lenguaje no como un reflejo pasivo de la realidad material, sino como un participante activo en la construcción de la realidad. La gramática explica y organiza el funcionamiento del lenguaje y de cada lengua en particular, y funciona como una totalidad, construyendo todas las experiencias humanas susceptibles de ser comunicadas y plasmando en un acto todas las interrelaciones subjetivas, y haciéndolo siempre en contexto. Al postular el aspecto social del lenguaje como parte inherente al sistema lingüístico, la gramática sistémicofuncional debe mostrar cómo es la relación que se establece entre el sistema y sus usos sociales. Siguiendo la idea de que el lenguaje tiene una función determinada en un contexto concreto, y que en los textos orales o escritos se representan personas que se relacionan entre sí, la gramática sistémico-funcional de Halliday, y su modelo de análisis llamado Transitividad (Halliday, 2004: 170), permite explicar las estructuras lingüísticas. Además, la Transitividad permite observar las diferencias entre los tipos de procesos verbales gracias a los que se puede comprobar cómo se representa en los textos que estas personas hacen cosas, crean cambios, expresan comportamientos, ven, sienten, piensan, hablan, tienen una identidad y unas características propias. La Transitividad consiste por lo tanto en un recurso gramatical apto para construir el flujo de la experiencia en términos de un proceso que se realiza gramaticalmente en una oración (Ghio \& Fernández, 2008: 93).

Por estas razones, retomaremos las teorías de la gramática sistémico-funcional para analizar, en primer lugar, los títulos de las canciones y sus tópicos, entendidos como el contenido semántico del texto.

En segundo lugar, estudiaremos las personas representadas en las canciones, y para ello observaremos los pronombres y los sintagmas nominales con los que se representan a la primera persona, la segunda, la tercera y la audiencia. Para prestar atención y estudiar las personas representadas y su función dentro de los textos de las canciones seguiremos los planteamientos de Van Leeuwen sobre la representación de los actores sociales en el discurso (1996).

En tercer y último lugar, siguiendo el modelo de la Transitividad estudiaremos los tipos de procesos y el co-texto en el que se insertan y en este caso se seguirán los postulados de la gramática sistémico-funcional de Halliday (2004). Los procesos 
que aparecen en los textos de las canciones están determinados por el tipo de actividad al que el verbo hace referencia. Halliday presenta seis tipos de procesos: Los procesos materiales expresan lo que los actores hacen a través de actos y sucesos concretos y abstractos (Halliday, 2004: 179). Los procesos mentales exponen las experiencias del mundo de las personas representadas desde la percepción, cognición y afectividad (197). Los procesos relacionales expresan lo que las personas representadas son y lo que tienen, de tal forma que los verbos "être" y "avoir" son los procesos relacionales típicos. Los procesos de comportamiento describen los actos fisiológicos y psicológicos. Además, los procesos verbales se sitúan en un lugar intermedio entre los procesos de relación y los procesos mentales y representan procesos del decir, se trata por tanto de lo que las personas representadas en los textos dicen. Los procesos existenciales se asemejan a los relacionales ya que cuentan con un participante implicado en un proceso de ser o existir, denominado existente. En este caso se expresa con "Il y a" o "Il fait" y muestra realidades inmutables vinculadas con las personas representadas o con otros elementos del co-texto.

\section{Análisis del título de las canciones}

La canción "Matabiau" (1995) lleva el nombre de la estación de tren de Toulouse. Se trata por tanto de un homenaje y un elogio (Aristóteles, 2001: 101, 103) a este espacio de la ciudad en la que los integrantes del grupo han pasado su vida desde su infancia. Para ello se emplea una nominalización (Van Leeuwen, 1996: 53) con un nombre propio que determina y delimita el objetivo de la canción.

Esta canción utiliza una técnica a modo de mosaico en la que se van insertando personas y acciones en relación con lo que sucede de forma cotidiana en el interior de este espacio con el objetivo de crear una visión en conjunto. El objetivo es moldear una imagen general de la función que tiene la estación de tren de Toulouse más allá de su actividad inherente. En esta canción se cuenta por tanto lo que sucede en la estación de forma cotidiana, y se hace referencia también a las personas que por allí pasan de largo a diario como pueden ser los turistas, pasajeros, o personas que entran para hacer alguna pequeña compra rápida. Así, aparecen en la canción personajes tales como vendedores, ladrones, trabajadores, personas sin techo que pasan allí la noche incluso en Navidad, y otras que están allí para pasar el tiempo y ver la gente ir y venir. En todo caso, la representación de la estación es positiva y tiene connotaciones afectivas marcadas por la abundancia de posesivos y de exclamaciones, que, a modo de elogio, alaban las cualidades y los beneficios comunes de esta estación.

En el título "Ma rue" (1995) se utiliza un posesivo seguido de un sustantivo concreto, de tal forma que mediante una posesivización (Van Leeuwen, 1996: 45) se marca la proximidad, la cercanía, la relación personal, el vínculo afectivo del "je" con el objeto o sustantivo poseído que, precisamente por utilizar el posesivo, forma de alguna manera parte de sí mismo. En esta canción aparecen una serie de colectivos representados como una alianza cuyo vínculo se fundamenta en el hecho de 
compartir el mismo espacio y en las relaciones entre las personas que aparecen representadas en él.

Para mostrar las personas vinculadas a la calle, se repite la técnica del mosaico y se van presentando elementos pequeños para construir un conjunto más grande, de tal forma que aparecen grupos de personas que dibujan la calle a la que se refiere. A ello contribuye también la técnica de personalización (Van Leeuwen, 1996: 59), que muestra a refugiados españoles, franceses que vivieron la ocupación alemana nazi, portugueses, isleños franceses del Caribe, africanos, gitanos, y muchos niños con sus madres.

En el mismo disco en el que se publicaron las dos canciones anteriores, aparece "Toulouse" (1995) que lleva por título el nombre de la ciudad francesa origen del grupo musical Zebda y de sus integrantes. La ciudad se convierte por tanto en un personaje protagonista de la canción debido a una sucesión de presentaciones en las que van apareciendo grupos de espacios y personas asociadas a él, empleando una vez más la técnica del mosaico. Por un lado, los barrios y zonas periféricas se dibujan con las vendedoras de las pequeñas tiendas o puestos de mercados ambulantes, los carteristas, los olores y sabores de la cocina mediterránea, los orígenes latinos y la música de diferentes procedencias que se entremezclan como el raï y la musette. Por otro lado, el centro de la ciudad se representa asociado a la vida burguesa de personas que viven en otro contexto económico y con otros intereses, como por ejemplo los trabajadores de la fábrica de aviones de Toulouse. De igual manera, se presentan los lugares de reunión de los anarquistas españoles exiliados así como las oficinas de las instituciones oficiales. Se plasman por lo tanto dos mundos diferentes en una misma ciudad que expresan las distancias sociales de los grupos marcada por la distancia geográfica que se crea en función de la distribución de los valores económicos y sociales (Bourdieu, 1988: 120-121).

En la canción "Né dans la rue", de nuevo se presenta el tema del espacio y de la calle por medio de una nominalización a partir de un participio pasado, y lo que Halliday denomina una circunstancia de localización en el espacio (Halliday, 2004: 262). En esta canción se relata cómo era la calle donde un "je" vivió su infancia. Al igual que en las canciones anteriores, se enumera una serie de espacios y personas de manera interrelacionada que dan una visión general subjetiva de un espacio muy determinado. La técnica que hemos denominado en las anteriores canciones como mosaico se emplea una vez más en esta canción para mostrar con minuciosidad una localización partiendo de historias personales íntimas y pequeñas. De esta forma se presenta una calle de un contexto social y económico desfavorecido donde conviven personas con diferentes culturas, gustos y tradiciones $\mathrm{y}$, al igual que en "Ma rue", y según cuenta el "je" siempre hay muchos niños, ya que "chaque jour on fêtait une naissance". Toda la canción es una oda a la calle con un interés especial en mostrar la inocencia de sus habitantes y donde reinan las relaciones de concordia, convivencia y tolerancia para los que allí viven. Sin embargo se reconoce también que la hospitalidad no se aplica de la misma forma para con las personas que no pertenecen a este entorno: "rue de " si t'es pas d'ici je t'escorte »". 
"On est chez nous" muestra un proceso relacional atributivo por el que se enuncia de forma afirmativa y asertiva una realidad que el "on" considera absoluta e irrefutable. Esta declaración categórica de sí mismo indica una necesidad de autojustificación o autolegitimación que se explica con la representación de un on cercado por una circunstancia de localización de espacio "chez nous". De esta forma la cláusula se abre y se cierra con el mismo pronombre personal, uno tónico y otro átono. Por consiguiente, son las mismas personas las que abren y cierran el enunciado encerrando en el interior el espacio al que se refieren, hermetizando e impermeabilizando así el grupo y el espacio que a sí mismos se asignan. Además, "chez nous", puede considerarse la expresión de una posesión, lo que enfatiza aún más el vínculo y la pertenencia del espacio al sujeto. De igual forma, hay que señalar que esta circunstancia espacial tiene un significado amplio o diferente dependiendo del co-texto. Por un lado, podría tratarse de su propio domicilio, un piso, un apartamento o una casa: por otro lado, puede referirse también a su propio país, o a la nacionalidad en términos del espacio en el que se ha nacido y del que se considera que la pertenencia es mutua. Esto señalaría que la persona pertenece al lugar en el que ha nacido, y el lugar en el que se nace pertenece a la persona que nace en él. Este título abre por tanto la puerta a una canción que argumenta y defiende los derechos de nacionalidad adquirida por nacimiento.

"On est chez nous" tiene como actor un "je" o un "on" que se dedica a lo largo de la canción a enumerar todo aquello que hace para defender el hecho de ser francés por haber nacido en Francia enunciado en el título, y que reclama hasta dieciséis veces en la canción diciendo "on est chez nous". La primera persona defiende también a lo largo de la canción otras causas como "la révolte des basses, le respect ne s'est jamais donné mais pris, je fais la marinade des peuples métisses, je fais la marche des exclus, je fais le mixe qui dégoûte pas du vote". Todas estas expresiones pretenden decir que el "je" hará todo lo que esté en su mano para luchar por sus derechos y en contra de la injusticia.

"Du soleil à la toque" (2002) trata de un título enigmático si se pretende buscar el significado en sí mismo puesto que las referencias se encuentran en el interior de la canción. Por lo tanto, aumenta la curiosidad de saber qué significa esta oración y a qué se refiere. Las razones gramaticales y lingüísticas de esta curiosidad se crean con la omisión voluntaria y explícita del sujeto "il" y del proceso existencial neutral formulado con el verbo "avoir". Al no aparecer estos dos elementos se crea un vacío de significado que no permite inferir a lo que se refiere, ya que el resto de la cláusula queda completamente descontextualizado y desco-textualizado. Sólo cuando se aborda el texto entero de la canción se descubre que se está hablando con nostalgia de las chabolas en las que vivían los obreros, trabajadores extranjeros y franceses de provincias durante los años veinte y treinta del siglo XX. Esta cuestión se refiere al hecho de que los inmigrantes procedentes de otros países y del éxodo rural se instalaban en las zonas periféricas de las ciudades, próximas a las vías de tren hasta que se empezaron a tomar las primeras medidas urbanísticas, provocando el surgimiento de zonas de viviendas inseguras, insalubres y que se convirtieron en verdaderos guetos de marginación (Winock, 2003; Ambrosi, 2004). De manera 
nostálgica, esta canción pone de relieve los aspectos positivos de lo que allí vivían y padecían sus habitantes. El hecho de dedicar una canción a este tema puede tener varias funciones: recordar a las personas que tuvieron que vivir en estas circunstancias, recordar los duros inicios de la población inmigrante en Francia, denunciar que en estas circunstancias no se estaba bien, pero que las soluciones urbanísticas posteriores, de las que hoy los mismos son hereditarios, no fueron las que se esperaban ni tampoco las que se prometieron. Igualmente, se denuncia que se prometieron viviendas para todos en mejores condiciones y que esas promesas no se cumplieron:

Un jour y sont arrivés en criant "n'ayez pas peur"/ On a vu la grue qu'a tout démoli en un quart d'heure/Là-bas vous aurez un jardin/ Et y'aura une salle de bain/ Ils avaient construit la cité/ Ce paradis qu'on devait habiter $[\ldots] /$ Mais à peine arrivés $[\ldots] /[\ldots]$ C'étaient vingt et un flics et un éducateur/ Qui nous on dit "c'est pas votre maison".

En resumen, en estas seis canciones se aborda el espacio desde diferentes panorámicas que en conjunto muestran una visión muy detallada de las situaciones y circunstancias asociadas al espacio. Esto se observa en los títulos y contenidos de las canciones que van desde los espacios más pequeños y privados, a los más amplios y públicos, como es la vivienda ("Du soleil à la toque"), siguiendo por la calle ("Ma rue", "Né dans la rue"), ampliando las vistas a lugares más alejados del entorno directo pero que siguen siendo zonas públicas a las que la primera persona se encuentra estrechamente vinculada ("Matabiau") para pasar a territorios más generales, abiertos, integradores de múltiples colectivos, multiculturales como la ciudad ("Toulouse") y terminar con áreas más amplias en las que se hace referencia al país, que darían lugar a abordar la cuestión del respeto a la nacionalidad ("On est chez nous").

Esta reflexión indica también la importancia que el espacio tiene para dar a conocer las cuestiones que se tratarán a lo largo de todo el análisis. Esto se debe a que los macrotemas de la discriminación, la familia, identidad, nacionalidad, y cuestiones laborales contienen como tema transversal el espacio ya que todas estos temas tratados surgen de los procesos de inmigración, de la mala gestión urbanística, y del malestar de un determinado colectivo de la sociedad con respecto a las cuestiones que están vinculadas directamente con el territorio francés. 


\section{Análisis de las personas representadas: primera y tercera persona, audiencia}

Según las canciones agrupadas en torno al macrotema del espacio, y en relación a las personas representadas en este grupo de canciones es conveniente dividirlas en dos grupos. Por un lado están las canciones "Du soleil à la toque" y "On est chez nous" en las que las personas representadas pertenecientes al grupo interno o endogrupo cobran mayor relevancia. Por otro lado, estarían el resto de canciones en las que la presencia del exogrupo es mayor que la del endogrupo. Como iremos viendo, la razón de esta división se debe al contenido de las canciones. Las primeras están más centradas en la experiencia personal de la primera persona con el espacio, y el resto plasma en forma de mosaico los diferentes grupos de personas que conforman un espacio, de ahí la gran cantidad de terceras personas.

En relación con el primer grupo de canciones, se observa que el empleo continuo y abundante de "je" en la canción "On est chez nous" y de "on" en la canción "Du soleil à la toque". En ambos casos se trata de una primera persona que se erige portavoz de un colectivo concreto, el de la segunda generación o los hijos nacidos en Francia de inmigrantes norteafricanos. La presencia de la primera persona es relevante porque de entrada marca la existencia de estas personas, efectuada con la enunciación reiterada de la primera persona. Son por tanto los protagonistas de los procesos y los que marcan la pauta del tema de la canción. Sin embargo, están recogidos bajo el macrotema del espacio porque se expresa la relación que las personas establecen con éste. En el caso de la canción "On est chez nous", aparece la persona "je" continuamente contando sobre todo lo que hace, de ahí el empleo de numerosos procesos materiales. Los músicos se erigen como portavoces de las causas de las minorías y sobre todo, con el empleo del pronombre "on" expresa con un proceso relacional contextual que se encuentran de forma legítima en su propia casa, y que por tanto pueden expresar y reivindicar de forma libre el hecho de que el lugar donde viven les pertenece por derecho propio de nacimiento. El hecho de repetir hasta 12 veces el estribillo "on est chez nous" muestra la necesidad de reconocimiento del espacio legítimo.

En otra ocasión, en las mismas canciones se cambia el significado del "on", e igualmente, la primera persona explica que el exogrupo pretende que el endogrupo deje de resistir y se sientan vencidos por el agotamiento de reivindicar su espacio legítimo "on voulait juste une seconde voir en nous, la sale bête qui dit « on est plus chez nous "»". En este caso, la primera persona del plural "on" cambia de significado y deja de ser sinónimo de "nous" para pasar a ser la tercera persona del plural "ils" o una forma impersonal. De manera que se emplea "nous" para referirse al endogrupo, y "on" para el exogrupo. Como muestra de rechazo y de contraste con este empleo de "on", a continuación se emplea la primera persona "je" que vuelve a retomar la palabra portavoz del colectivo representado. Esta alternancia del significado de la primera persona, enfatiza la presencia del "je" y muestra de manera clara las relaciones de contraste entre el endogrupo y el exogrupo, explicitando la amenaza que supone el exogrupo al que el "je" quiere resistir con todas sus fuerzas: "je 
fais la pluie pour ça, je fais même le cri, on se fout des manières et du Prix, pourvu que nos chemises soient réduites en éponge!".

En el caso de la canción "Du soleil à la toque" se utiliza casi sistemáticamente el pronombre "on" para designar al centro deíctico. El empleo de "on" pretende la identificación del emisor con sus iguales (Maingueneau, 1991: 111-112) por lo que con este pronombre se evoca a muchas personas que se encontraban en la misma situación que el emisor. Por lo tanto, el hecho de que vivieran en chabolas y les pasaran a las cités formados por $\mathrm{HLM}^{2}$ es una circunstancia que padecieron todas aquellas personas representadas con el "on". La formación de un grupo con este pronombre repetido en hasta quince ocasiones señala la necesidad de detallar las circunstancias, los hechos y los procesos asociados a este colectivo que consiguen dar una imagen de un grupo numeroso que se muestra fuerte ante la adversidad. En algunos casos va asociado al on la primera personas del plural "nous", aparecen juntas y su objetivo es enfatizar la importancia del endogrupo "nous, on a refait les couleurs; mais nous, on avait déjà tombé la cloison" y marcar implícitamente las fronteras del grupo (Mainguenau, 1991: 112). Estas serían por tanto las características de estas dos canciones que centran la atención en el vínculo entre las personas y el espacio en el que habitan.

Por lo tanto, en relación con la primera persona de las canciones vistas hasta aquí, se observa como ésta se erige portavoz de un colectivo y expresa la relación que las personas establecen con la ciudad en la que habitan. Se trata de una petición de reconocimiento legítimo del espacio mostrado a través de las relaciones de contraste entre el endogrupo y el exogrupo que aparecen en el texto. Por esta razón, y en vistas a una identificación del emisor con la audiencia, se justifica esta necesidad de detallar las circunstancias, los procesos y los hechos, ya que así se pretende crear una imagen de colectivo que lucha contra sus problemas.

Con respecto al segundo grupo de canciones, se observa que la presencia de la primera persona es mucho menor y que se emplea, además del "on", el pronombre “je". Este fenómeno señala dos cuestiones: por un lado se deja más protagonismo a los elementos del espacio, y por otro el portavoz aparece personalizado y delimitado gracias a procesos relacionales que lo asocian de manera explícita con el espacio: "Toulouse, on t'explose, je suis né dans la rue, je suis né dans cette rue". Esto indica que la primera persona aparece representada y sirve de anclaje con el espacio, pero es en realidad éste el que es protagonista, algo que podrá comprobarse y verse con más detalle en el análisis de la tercera persona. Es significativa por tanto la

\footnotetext{
${ }^{2}$ Habitation à loyer Modéré (HLM) típicos ya del paisaje urbanístico de las grandes ciudades francesas. Se trata de bloques de edificios construidos con prisa, de mala calidad, de bastante altura, situados siempre en la periferia de las grandes ciudades que alojan a miles de personas. Por poner un ejemplo ilustrativo, en el barrio de Minguettes de París existen más de 9000 viviendas de estas características (Marx-Scouras, 2005: 44-45; Noiriel, 2006: 175-176).
} 
menor presencia de las primeras personas en canciones para dar paso a una representación detallada de la tercera que contribuirá a la representación positiva del espacio, centrado sobre todo en la calle, la ciudad de Toulouse, y su estación de tren Matabiau.

Sin embargo, se encuentra una excepción a esta generalidad que acabamos de explicar en la canción "Toulouse". En este texto hay un gran número de primeras personas vinculadas al espacio, pero esta mayor presencia se debe a que en la canción aparece de forma manifiesta el emisor y el autor Zebda que explica la presencia del pronombre "on" o "je". Son ellos los que toman la palabra y los que se identifican como tal dentro de la canción: "Zebda catapulte, Zebda vous confirme ici". Aquí hay una representación auténtica de una persona o un grupo que toma la palabra dentro del texto "nous qui vivons de Raï de Rock et de Musette, à la périphérie des succès cathodiques". En el texto la persona representada como Zebda aparece utilizando su nombre como una tercera persona, y después retomado con el pronombre "nous". El hecho de aparecer nombrados muestra una representación que no deja lugar a dudas del grupo representado gracias a la nominalización (van Leeuwen 1996: 52). Por su parte, el adjunto "ici" aproxima a esta persona representada al centro deíctico. Aparte, el "nous" detalla a qué se dedica el grupo a través de la funcionalización (van Leeuwen 1996: 54) y les representa por tanto en términos de lo que hacen, que indudablemente se refiere a la música. Con esta estrategia se llama la atención de la audiencia que se ve sorprendida por la irrupción de estas personas en el texto. Además, Zebda se dirige a ellas de forma directa con un proceso verbal y el pronombre indirecto "vous". Esta auto-representación positiva trata de establecer así una conexión cercana entre el emisor y el receptor. De igual forma, el nombre de la ciudad "Toulouse" se muestra como pronombre referencial sujeto externo asociado a procesos existenciales que representan el espacio delimitado en la ciudad de Toulouse.

La localización del endogrupo en la canciones "On est chez nous" y "Du soleil à la toque" se observa en la relación de oposición con respecto a la tercera persona "ils", a quienes se atribuye el desalojo de las chabolas "un jour (ils) y sont arrivés en criant « n'ayez pas peur »", y la construcción de los edificios de mala calidad "ils avaient construit la cité". La tercera persona "ils" por tanto se señala aquí como la encargada de realizar la acción que provoca el malestar del endogrupo con el uso del deíctico que marca la mayor distancia con respecto al centro deíctico y que establece una relación de contraste entre lo representado en el discurso cercano al hablante y lo que se representa alejado (Verschueren, 1999: 18; Yule, 1996: 9). Es importante señalar que aparecen muchos procesos asociados al endogrupo y muy pocos al exogrupo. Esto se debe a que los elementos más próximos al centro deíctico se formulan de forma detallada. Sin embargo, cuanto más alejado del centro deíctico está la persona, más difusos y generales serán los argumentos. Ésta es la forma en la que se codifican las actitudes e ideologías subyacentes a un discurso, dibujando una línea imaginaria entre los miembros del grupo y los que están fuera de éste (Van Dijk, 2003: 60-63). 
Las terceras personas expresadas con sintagmas en la canción "On est chez nous" se representan igualmente en una relación de oposición con respecto al centro deíctico empleando la nominalización, una técnica que simplifica las realidades complejas, muestra generalizando, y a través de la abstracción difumina sus rasgos tanto positivos como negativos (Halliday, 2004: 636-639; Kress, 1979: 26-27): "le respect, les grands, la sale bête". El uso de estos nombres evoca a cuestiones más amplias como en el caso de "la nuit qui (ne) fait pas rire aux notables" que se refiere los actos que critican a los poderosos y que les molestan, "le respect (ne) s'est jamais donné", se refiere a la necesidad de la búsqueda de la justicia, "les grands qu'(n') ont jamais" se refiere a los poderosos, a los políticos, "la sale bête qui dit « on (n') est plus chez nous »" con un insulto se refiere a los miembros del exogrupo que atacan al endogrupo. Hay que señalar el uso de un nombre de cualidad despreciativo o insulto en "sale bête" que normalmente está asociado a una apreciación del emisor (Maingueneau, 1991: 119). En este caso, se trata de un insulto directo proferido a una persona externa no concreta que surge por las palabras de una tercera persona que tiene como objetivo denunciar y reaccionar a través de una transgresión verbal compensatoria, de ahí el hecho de que se utilice un registro de lengua vulgar (Adam 1999: 163).

Todas estas terceras personas se enuncian con negación y expresan un valor interpersonal negativo. Ello imprime de connotaciones negativas al co-texto y a estas personas representadas, ya que modula el enunciado mostrando a la audiencia el lado negativo que le interesa. Por el contrario, cuando se refiere a "las castagnettes" se utiliza un artículo y un nombre común concreto, en forma afirmativa, con valor interpersonal de actor. Se expresan así como una tercera persona cercana al endogrupo, como son los españoles que llegaron exiliados durante la Guerra Civil española. Este uso demuestra que la nominalización en la tercera persona refiriéndose al exogrupo constituye una estrategia más de deslegitimación de la tercera persona que se enfrenta al centro deíctico.

La utilización del sintagma nominal con nombres comunes concretos en la tercera persona es muy común en la canción "Du soleil à la toque". En esta canción se enumeran los elementos y objetos relacionados con el espacio, en este caso inmobiliario y urbanístico, y se realiza una representación negativa de los valores interpersonales, de los verbos en forma y de la evaluación: "si les robinets d'eau n'étaient pas trop loin, l'eau faisait gris à la mairie, la maison finit en petit tas de sable". Se trata por tanto de una representación de los elementos integrantes del espacio que tienen como objetivo denunciar la mala calidad de las viviendas y criticar de manera indirecta a los que decidieron construir estos H.L.M.

En otras ocasiones la tercera persona sirve para mostrar el paisaje que rodea al centro deíctico, de ahí que en "Né dans la rue" los sintagmas nominales se refieran a elementos del entorno desde lo más concreto a lo más abstracto. Así aparecen referencias culinarias tales como "la tomate", "le champagne", "la friture", una cuestión que se emplea en reiteradas ocasiones en las canciones. Se hace referencia a las personas que se representan con nombres comunes concretos "les filles" o con metonimias "les têtes". Naturalmente aparecen los elementos espaciales propiamen- 
te dichos "une rue", medios de transporte como "la caravane" para terminar con términos que se refieren a elementos abstractos referidos a la existencia común de las personas representadas dentro de este espacio como "la vie, le temps". Estas terceras personas referidas a los alimentos, las personas, la calle y el tiempo señalan elementos particulares para mostrar una imagen general, a modo de mosaico. El alto nivel de detalle de la descripción del espacio, en este caso la calle, demuestra la intención de manifestar una representación positiva del espacio, por lo tanto, estaríamos ante una defensa de los espacios abiertos que rodean al individuo de manera más cercana, esto es, la calle, el barrio y las personas que viven en él.

La misma técnica es utilizada en la canción "Ma rue", sólo que en este caso la tercera persona es representada o bien por su nacionalidad "des espagnols, des français, des portugais", o por su vínculo familiar "les mamans, les enfants". En este caso aparecen personas que se refieren a colectivos muy concretos, individualizando el mosaico. Se trata por tanto de un paisaje humano asociado a procesos materiales en los que los sujetos son actores. Se consigue así mostrar la vida de la calle, el movimiento, los cambios producidos por las personas que conviven en un mismo espacio. Una forma de mostrar el entendimiento y el multiculturalismo que existe en las calles y en todo el territorio francés.

De igual forma se lleva a cabo la representación de la tercera persona en "Matabiau". En esta canción aparecen diversas personas que podríamos dividir en dos grupos. Por un lado, se muestran las personas típicamente asociadas a una estación de tren y que forman parte de su definición "des touristes, des voyageurs, les huissiers, des garçons et des filles". Estos serían los inherentes a este espacio tratándose por tanto de las personas que están de paso porque viajan y se sirven de las funciones de este servicio público. En este caso se presenta un paisaje personal e individual a modo de mosaico en el que se presenta un cuadro panorámico de la población de este espacio.

Por otro lado, para referirse a las personas que no forman parte de una estación de tren de forma habitual o estereotipada se emplean pronombres como "on", "elle", "ils", "ceux qui" o "chacun", "beaucoup". Tanto los pronombres del endogrupo como los de exogrupo se centran en la representación de las personas englobadas dentro del espacio delimitado por la estación de ferrocarril. La utilización de pronombres indefinidos indica una generalización y una apertura a un espacio que pretende ser un lugar de unión de diversos colectivos. Esto se interpreta como una representación positiva de este enclave, asociado a la ciudad de Toulouse, una ciudad que constituye un lugar de paso y/o de encuentro de personas muy diferentes que conviven y se interrelacionan en armonía.

El empleo en "Matabiau" del pronombre "on" como tercera persona se entiende como forma impersonal "on rit, on pleure, on fait la prière ou on mange un mauvais sandwich". Este uso tiene un objetivo de generalización para indicar que son muchas las personas que repiten estas actuaciones a diario. Asimismo, se le da amplitud y extensión a este colectivo, le otorga importancia, les hace visibles y cada uno dispone de una oración en el texto para que el mosaico de personas sea más preciso, abundante, colorido y atractivo, lo que constituye por tanto una representación 
positiva de la estación de tren de la ciudad de Toulouse. Del texto se extrae entonces la idea de que se trata de un espacio público que pertenece a todos, a los que están de paso, a los que trabajan allí, y todo aquel que quiera permanecer por la razón que le parezca oportuna. En todo caso, se trata de un espacio del que nadie se apropia, sino que se comparte y se tolera la presencia de todas las personas que quieran estar allí.

En relación con esta representación positiva, recordamos que los integrantes del grupo musical Zebda han nacido y desarrollado sus vidas personales y profesionales en Toulouse, por lo que esta canción tiene rasgos para convertirse en un homenaje a la estación de tren, como el empleo anafórico del apóstrofe: "Oh Matabiau, oh Matabiau, Matabiau" o comparaciones de superioridad, "c'était mieux qu'une station balnéaire, c'était ma gare".

Algo similar al procedimiento de la representación de la tercera persona en las canciones anteriores se desarrolla en la canción "Toulouse". La tercera persona se forma a partir de referencias culinarias a "la cuisine", "les restos", de personas "les bas", "les mômes", "les vendeurs", "le peuple", de las calles "la rue", de los elementos naturales como el río "la Garonne" y "le cie"l, y del conjunto de las ciudades "toutes les villes". Este mosaico que se representa en el texto proporciona un paisaje general de la ciudad, una visión panorámica de la vida en las calles de personas que conviven en aparente harmonía. Al igual que "Matabiau", esta canción se convierte en una alabanza explícita de esta ciudad en la que se hace sin reservas una representación positiva de este espacio, incluso en ocasiones idealizada, como se puede observar en "le peuple vient faire sa fête sur des hymnes romantiques".

Las terceras personas representadas en este grupo de canciones dedicadas al espacio son por lo tanto las que dibujan el entorno humano y urbanístico. Para ello se representan los elementos que rodean al centro deíctico circunscribiéndoles a unos emplazamientos determinados que van desde el alojamiento hasta el propio país, pasando por las calles, el barrio, la estación y la ciudad. En general, estos territorios aparecen representados positivamente aunque en el caso de la canción "Du soleil à la toque" sea negativo constituyendo así una crítica. En las canciones hay un gran número de personas vinculadas al espacio que en muchas ocasiones son las encargadas de mostrar el panorama que rodea al centro deíctico. Para ello se refieren a elementos concretos como las calles, las personas o los alimentos que muestran en realidad una imagen general. En este sentido, por un lado, determinadas terceras personas se representan alejadas o en relación de oposición con respecto al centro deíctico. Para lograr este efecto se destacan determinados aspectos negativos que al emisor le interesa. Por otro, se hace referencia a colectivos muy concretos que señalan a personas en conjunto y a nivel individual a modo de mosaico para mostrar así un cuadro basado en la democratización del espacio público. Por esta razón, se manifiesta una representación positiva del espacio y una defensa de los espacios abiertos de la ciudad.

En relación con la audiencia, aunque en alguna canción como "Ma rue" hay una omisión total de ésta, en otras sí aparece a pesar de que su presencia sea escueta. En la canción "On est chez nous", por ejemplo, la audiencia aparece reflejada en proce- 
sos verbales imperativos "allez rajoute, ne m'envoies pas dans les ronces" en los que se llama la atención del receptor pidiéndole directamente que actúe, refiriéndose a él mediante la segunda persona y mostrando un interés por mantener una distancia corta entre el emisor y el receptor.

En otros casos aparece reflejada con un "tu" que se identifica realmente con una primera persona portavoz como en el caso de "Né dans la rue" o "Du soleil à la toque" "tu dormais à la belle étoile même sous un toit, tu avais froid même avec une couverture sociale, tu pouvais toujours danser et chanter des slogans". Al decir "tu" está refiriéndose a la audiencia pero dicho deíctico busca la comprensión de la audiencia a través de la función fática del lenguaje que pretende confortar la relación social que existe entre los participantes del intercambio comunicativo. Se pretende mostrar a la audiencia que no se olvidan de sus preocupaciones y que se tienen en cuenta porque son las mismas por las que lucha el emisor, lo cual es una estrategia que intenta influir en el pensamiento de la audiencia para conseguir la adhesión de ésta a los intereses del emisor (Resche, 2005: 159).

Para terminar, hay que señalar que independientemente de la mayor o menor legitimidad que tengan las reivindicaciones de los textos de las canciones del grupo Zebda, y de si las reclamaciones son más o menos comprometidas con las minorías, con las causas relacionadas con los problemas de los inmigrantes, de los trabajadores, de los ciudadanos en general, en su discurso, esto es, en los textos de sus canciones, se emplean estrategias lingüísticas para acercarse al auditorio o a la audiencia, lo que crea un discurso comprometido pero también ideológico. Esto implica que muchas de las estrategias que estamos aquí analizando forman parte del modus operandi del discurso político propiamente dicho que se identifica con el que se utiliza en los mítines, en debates políticos, en los parlamentos, el senado, el congreso, y en otros contextos políticos. Ya que, al igual que en los textos de las canciones, la política se basa en disputas y luchas que suceden en la lengua y más allá de la lengua (Fairclough, 1989: 23). Por lo tanto, parece lógico que el debate político propiamente dicho y la canción socialmente comprometida se asemejen y que en numerosas ocasiones compartan las mismas estrategias de persuasión y de captación de seguidores.

\section{Análisis de la Transitividad: procesos materiales, procesos mentales, procesos verbales, procesos de comportamiento y procesos relacionales}

En el análisis de la Transitividad se puede observar que al estar describiendo espacios se está contando cómo son los elementos que configuran el entorno exterior, abierto y común. Así se explica la presencia numerosa sobre todo de los procesos materiales, relacionales y existenciales, además de los verbales y mentales, que aparecen aunque en menor número. Esta selección muestra que el interés se centra en la acción, en lo que hacen las personas representadas revelado gracias a los procesos materiales y en la descripción de los espacios, ejecutado con los procesos 
relacionales y existenciales, que emplean para expresarlo los verbos "être" y "avoir", que son por excelencia los verbos que muestran los procesos relacionales.

En relación con los procesos de comportamiento, sólo aparecen en la canción "Du soleil à la toque" en forma de procesos fisiológicos. Recordamos que esta canción se refiere a las malas condiciones de vida en las chabolas y el paso a los HLM que tampoco fueron una solución acertada. Por lo tanto esta canción cuenta que las personas que habitaban estas viviendas padecían sufrimiento físico por la falta de higiene, de servicios mínimos de habitabilidad y de espacios preparados para la convivencia, como se ve en el ejemplo siguiente: "Même sous un toit tu dormais à la belle étoile, tu avais froid même avec une couverture sociale, on dormait tous au fond de tout petits placards".

El hecho de que sea sólo en esta canción donde aparecen se debe a que realmente es la única en la que se hace una crítica al espacio mediante la reivindicación de una vivienda digna y de un emplazamiento urbanístico en el ámbito de la ciudad adecuado a las características de la nueva sociedad que se crea. Se trata por tanto de una representación negativa que denuncia las malas condiciones de vida de las minorías pobres y de la clase trabajadora, así como de la ineficacia de las propuestas de las instituciones para arreglar la situación.

Los procesos relacionales así como los existenciales describen el panorama físico que se pretende representar. En concreto, con los procesos atributivos intensivos en forma negativa se dice lo que algo no es como forma de denunciar lo que debería ser: "une rue qui n'était pas les Beaux Arts, ce n'est pas la rue des déclinaisons latines, ce n'était pas ma cabane au Canada, ce n'était pas les Antilles, le marteau ou la faucille". Al utilizar la negación "ne...pas" se profiere un enunciado rechazado sin dar la contrapartida positiva (Maingueneau, 1991: 131) y al decir lo que no es "beaux arts", "déclinaisons latines", "ma cabane au Canadá", "les Antilles", "le marteau", "la faucille" el emisor interviene en el discurso presentando la selección de lo que "no es" para mostrarla y enfatizarla gracias a la negación, lo que constituye una forma de intentar convencer y persuadir. Además, la selección de lo que "no es" está cargada de referencias que no son gratuitas, puesto que al decir "beaux arts" se refiere a los museos de cada ciudad en los que se exponen las obras artísticas más famosas, bellas, reconocidas, caras y estéticas, indicando con esta relación de contraste la falta de belleza de la calle en la que vive. De igual forma, al nombrar las declinaciones latinas puede estar evocando o bien la falta de cultura de sus habitantes, o bien el origen de los idiomas que éstos hablan, que no siempre es el francés que procede del latín, sino que se refiere al árabe. Asimismo, cuando dice: "ma cabane au Canadá" se refiere a una canción de la cantante Lina Renaud titulada así muy conocida en Francia en los años cincuenta3 que pertenece al género de las

\footnotetext{
3 "Ma cabane au Canada" es uno de los muchos éxitos de la cantante Lina Renaud. Esta canción es conocida por ser la vencedora del festival de Eurovisión de 1950. En el texto de la canción de Zebda
} 
"variétés françaises". En esta canción se habla de una vivienda idílica, en un entorno natural bucólico e idealizado, todo lo contrario por tanto de lo que es realmente una vivienda en un HLM o de las chabolas que se describen en la canción de Zebda. Finalmente, al referirse a las Antillas está haciendo un guiño a los territorios franceses de ultramar, y en "le marteau et la faucille" se refiere al martillo y la hoz símbolo gráfico del comunismo. En definitiva, la negación asociada a procesos relacionales, y también existenciales, es en este caso una manera de mostrar el punto de vista ideológico del emisor y una forma de conducir implícita y sutilmente el pensamiento de la audiencia.

Existe una importante presencia de la atribución intensiva que permite la descripción del espacio - "les robinets de l'eau n'étaient pas trop loin" - y de las personas "on était rachitique" que junto con el co-texto muestran una imagen en unos casos implícitamente negativa como en el caso de estos ejemplos extraídos de la canción "Du soleil à la toque", o una visión positiva como en el caso de la canción "Toulouse" o "Matabiau". "Toulouse est la ville rose, Toulouse est de plus en plus rose. C'était ma gare, c'était mieux qu'une station balnéaire ». Esto tipo de procesos están muy ligados a los procesos existenciales, muy abundantes en las canciones que se refieren al espacio ya que son los encargados de dibujar el paisaje: «il y avait des poux, il y avait des espagnols, il y avait l'Afrique et son mea culpa,il y avait tous les ouvriers de la terre, il y avait des caravannes". De manera que los procesos existenciales y relacionales cobran gran importancia ya que son los encargados de mostrar la imagen que se pretende proyectar a la audiencia del territorio al que se están refiriendo.

Los procesos materiales de acción representan hechos que expresan cambios que suceden en el mundo material como el movimiento en el espacio o cambios en el estado físico de las cosas. Por su parte, los procesos materiales de hecho, construyen cambios que tienen lugar en fenómenos abstractos. En el caso de este grupo de canciones agrupadas bajo el macrotema del espacio se observa un gran número de procesos materiales que indican el movimiento, la vitalidad, el trabajo de las personas representadas: "nos parents ont construit de leurs mains, ils avaient construit la cité". La continua presencia del verbo "faire" es significativa, sobre todo en la canción "On est chez nous" en la que aparece hasta diecisiete veces: "je fais lever les bras", "je fais la révolte de basses", "je fais la nuit", "je fais la marinade des peuples métis", etc. Este verbo, empleado ya sea en sentido literal, o bien como un proceso material abstracto, indica con su profusa presencia la necesidad por parte del emisor de mostrar que las personas representadas se mantienen activas, que

se utiliza la intertextualidad refiriéndose a la canción de Renaud que dice "Ma cabane au Canada/ C'est le seul bonheur pour moi/ La vie libre qui me plaît [...] Ma cabane au Canada/ Tant que tu y resteras/ Ce sera le paradis/ Mon chéri/ A quoi bon chercher ailleurs/Je sais bien que le bonheur/ Il est là/Dans ma cabane au Canada". 
hacen muchas cosas y que producen cambios. Las acciones y los cambios forman parte también del paisaje que se dibuja a lo largo de las canciones con diferentes estrategias. En este sentido, el hecho de emplear muchos procesos materiales y de repetir de manera insistente el verbo "faire" contribuye al diseño y colorido de los espacios representados. Se muestra así una vivienda, una calle, una ciudad o una estación activa, llena de gente que va y viene, que vive allí, que trabaja, y que se divierte. En definitiva, se plasma un retrato verosímil de la vida desarrollada en estos espacios.

Los procesos materiales de hecho están muy vinculados a los procesos relacionales y existenciales puesto que plantean verbos que expresan acciones y que se enlazan con la existencia de las personas representadas: "on vivait comme des Indiens", "on vivait dans des baraques en bois", "on devait habiter ce paradis", "ils n'habiteront jamais". Una vez más estos procesos ayudan a comprender las características físicas del espacio representado y de las personas que habitan en él. Colaboran por tanto en la representación ya sea negativa ("Du soleil à la toque") o positiva del espacio apoyando con los actos propiamente dicho en la construcción de un territorio que se representa en general de una forma positiva, cercana, activa, poblada de personas que le dan vida y que dan significado a las zonas de la ciudad en las que están inmersos.

\section{Conclusión}

El método lingüístico que hemos empleado nos permite seleccionar y organizar la información que se presenta en los textos de manera que facilita la comprensión de las estrategias empleadas para la transmisión de los contenidos que el emisor está interesado en difundir. De esta forma podemos observar que se emplea a menudo la auto-representación positiva y la representación negativa del otro. A través de estos conceptos hemos podido observar cómo se construye un discurso ideológico en el que se destacan y detallan los aspectos positivos del centro deíctico, y los negativos de los alejados, los considerados "los otros", dejando difusos los aspectos negativos del centro deíctico así como los rasgos positivos del exogrupo. Así se codifican las actitudes e ideologías subyacentes del discurso, dibujando una línea imaginaria entre los miembros del grupo y los que están fuera de éste (Van Dijk, 1997: 28; 1999: 57, 60-63).

Las canciones analizadas muestran el espacio como elemento socializador incluso cuando se trata de espacios que forman parte de territorios asociados con la exclusión social. Las canciones dedicadas a las chabolas y al HLM señalan unas zonas de la ciudad generadas por la inmigración y la mala gestión urbanística de las que los ciudadanos han sido y son víctimas. Sin embargo, incluso en la descripción de las personas y de los procesos asociados al espacio, éste siempre aparece como un punto de encuentro común conciliador del que el emisor se siente parte integrante, e incluso hacia el que muestra cierto sentimiento. 
En las canciones se realiza una representación del espacio urbano positiva, cargada de afecto y viveza, sobre todo en el caso de las canciones en las que se habla de la estación de tren y de la ciudad de Toulouse. Por lo tanto, las estrategias lingüísticas se ponen al servicio de una imagen alegre, viva y colorida de una ciudad activa, trabajadora, pluricultural, cargada de vínculos afectivos con las demás personas que comparten estos espacios y con el suelo propiamente dicho. En la canción "On est chez nous" llama la atención que el grupo musical Zebda aparezca de manera explícita. Este fenómeno deja a la vista las preferencias personales de los integrantes del grupo y del autor del texto, que no esconden el afecto a la ciudad de Toulouse y todo lo relacionado con ella. De igual forma, no hay que olvidar que se trata de una forma de reivindicación del espacio público que, sin pertenecer a nadie, pertenece a todos por igual. Esto indica que se representa en el discurso un espacio democrático, tolerante, multicultural, plurilingüe y libre, que sin embargo necesitan reclamar y que justifica la existencia de estas canciones con un tópico común claro centrado en los fuertes vínculos sociales y afectivos que existen entre los ciudadanos con el espacio que habitan.

\section{REFERENCIAS BIBLIOGRÁFICAS}

Discografia

Zebda, (1992) L'arène des rumeurs. Barclay/Poligram, France.

- (1995) Le Bruit et l'odeur. Barclay/Poligram, France.

- (1998) Essence Ordinaire. Barclay/Poligram, France.

- (2002) Utopie d'occase. Barclay/Poligram, France.

Obras consultadas

Adam, J-M., (1999) Linguistique textuelle. Des genres de discours aux textes. Paris, Nathan Université.

Ambrosi, C.; Ambrosi, A. \& B. Galloux-Fournier, (2004) La France de 1870 à nos jours. Paris, Armand Colin.

Aristóteles, (1991) The art of Rhetoric. Trad. \& ed. J.H. Freese, Cambridge, Harvard University Press.

Bizzoni, L. \& C. Prévost-Thomas, (2008) La chanson francophone engagée. Montréal, Triptyque.

Bourdieu, P., (1982) Ce que parler veut dire. Paris, Fayard.

- (1988) La distinción. Madrid, Taurus.

Calvet, L-J., (1981) Chanson et société. Paris, Payot.

- (2008) Cent ans de chanson française. Paris, Archipoche.

Dutheil Pessin, C., (2004) La chanson réaliste. Sociologie d'un genre. Paris, L'Harmattan.

Eco, U., (2007) Apocalípticos e integrados. Barcelona, DeBolsillo. 
Faircloug, N., (1989) Language and power. London/New York, Longman.

Ferréol, G. \& G. Jucquois, (2004) Dictionnaire de l'altérité et des relations interculturelles. Paris, Armand Colin.

Fijalkow, Y., (2002) Sociologie de la ville. Paris, La Découverte.

Ghio, E. \& M. D. Fernández, (2005) Manual de gramática sistémico funcional. El enfoque de M.A.K. Halliday y R. Hasan: aplicaciones a la lengua española. Santa Fe, Universidad Nacional del Litoral.

Iglesias Botrán, A. M., (2011) "La canción francesa como transmisora de ideologías: un análisis lingüístico" in Synergies Espagne. № 4, pp. 77-84.

Halliday, M.A.K., (2004) An introduction to Funcional Grammar. London, Hodder Education/Hachette UK.

Kress, G. \& R. Hodge, (1979) Language as ideology. London, Routledge/Kegan Paul.

Marc Martínez, I., (2008) Le rap français. Esthétique et poétique des textes (19901995). Bern, Peter Lang.

Marx-Scouras, D., (2005) La France de Zebda 1981-2004: Faire de la musique un acte politique. Paris, Autrement.

Maingueneau, D., (1991) L'Analyse du discours. Introduction aux lectures de l'archive. Paris, Hachette Supérieur.

Noiriel, G., (2006) Le creuset français. Histoire de l'immigration. XIX ème-XXème siècle. Paris, Seuil.

Reijasse, J., (2002) Zebda de A à Z. Paris, L'exprès Roularta.

Resche, C., (2005) "Le discours officiel du Président de la Réserve Fédérale américaine : entre transparence et propagande" in Banks, D. (éd.), Aspects linguistiques du texte de propagande. Paris, Harmattan.

Semprini, A., (1997) Le multiculturalisme. Paris, PUF, coll. Que sais-je ?

Van Dijk, T.A., (1997) "What is Political Discourse Analysis?", in Blommaert, J. \& C. Bulcaen, (ed.) Political Linguistics. Amsterdam, John Benjamins, pp. 11-52.

Van Dijk, T.A., (2003) Ideología y discurso: una introducción multidisciplinaria. Barcelona, Ariel.

Van Leeuwen, T., (2000) "Semiótica discursiva" in. Van Dijk, T. (ed.), El discurso como estructura y proceso. Estudios sobre el discurso I. Una introducción multidisciplinaria. Barcelona, Gedisa, pp. 373-416.

- (1996) "The representation of social actors" in Caldas-Coulthard, C. R. \& M. Coulthard (ed.), Text and Practices: Readings in critical discourse analysis. London, Routledge, pp. 32-70.

Vershueren, J., (2002) Para entender la pragmática. Madrid, Gredos.

Winock, M., (2003) La France politique. XIX $X^{e} X X^{e}$ siècles. Paris, Seuil.

Yule, G., (1996) Pragmatics. Oxford, Oxford University Press. 